\title{
Some aspects of design and application of inertial dampers
}

\author{
Maciej Dutkiewicz ${ }^{1 *}$, Irena Gołębiowska ${ }^{1}$, Ivan Shatskyi ${ }^{2}$, Vasyl Shopa $^{2}$, and Andrii \\ Velychkovych ${ }^{3}$ \\ ${ }^{1}$ University of Science and Technology, Faculty of Civil, Environmental Engineering and \\ Architecture, Al. Prof. S. Kaliskiego 7, 85-796 Bydgoszcz, Poland \\ ${ }^{2}$ Ivano-Frankivsk Branch of Pidstryhach-Institute for Applied Problems in Mechanics and \\ Mathematics, NAS of Ukraine, Department of modelling of damping systems, Mykytynetska 3, \\ 76002 Ivano-Frankivsk, Ukraine \\ ${ }^{3}$ Ivano-Frankivsk National Technical University of Oil and Gas, Department of Structural \\ Mechanics, Karpatska 15; 76019 Ivano-Frankivsk, Ukraine
}

\begin{abstract}
Over the last years, there has been intensive development of technologies applied to protect structures such as overhead transmission lines, chimneys, high rise buildings from excessive dynamic effects leading to their damage or destruction. In the paper special attention is put on the system of passive dampers applied to overhead transmission lines and dampers used in oil and gas industry. The efficiency of the aeolian damper is presented. The constructions of weighted drill pipes with vibration-impact particle dampers designed to absorb the energy of longitudinal and twisting oscillations of the drill tool are described. The advantage of a multi-container absorber is substantiated. The application aspects of the inertial dampers developed by the authors are combined using a common effect based on the antiresonance phenomenon.
\end{abstract}

\section{Mechanical dampers used on overhead transmission lines}

Overhead transmission lines are constantly subject to variable wind loads which may gradually lead to the impairment of their durability, resulting in the shortened service life. Wind forces are caused by three main types of conductor vibrations: aeolian vibrations with a frequency from 3 to $150 \mathrm{~Hz}$ and amplitudes lower than the conductor diameter, galloping with a frequency from 0.1 to $1 \mathrm{~Hz}$ and amplitudes from \pm 0.1 to 1 of conductor sag, wake induced vibrations with a frequency from 0.15 to $10 \mathrm{~Hz}$ and amplitudes from 0.5 to 80 times the conductor diameter [1].

The majority of common wind induced vibrations are aeolian vibrations. These vibrations are generated as a result of vortices shed in the conductor wake under sustained wind of low speed from 1 to $7 \mathrm{~m} / \mathrm{s}$ - they occur mainly in the vertical plane.

Another phenomena of vibrations of overhead transmission lines is galloping. Galloping is an aeroelastic self-excitation phenomenon characterised by low frequencies and high amplitudes, and it refers to single conductors and conductors in a bundle, with one or two

*Corresponding author: macdut@utp.edu.pl 
loops of standing and running waves, or their combination in a conductor span. A conductor of a circular section cannot gallop due to its geometrical symmetry $(\mathrm{dCL} / \mathrm{d} \alpha=0)$, unless this section is changed. Icing of a conductor changes its cross-section, thus it leads to its aerodynamic instability [2]. The effect of a coupled torsional-translational motion plays a crucial role in most cases of progressing galloping [3].

Stockbridge dampers are most frequently used dampers on overhead power lines Figure 1. A classic Stockbridge damper consists of two 'inertial masses' $m_{1}$ and $m_{2}$ (metal weights) clamped at the ends of a specially designed short steel wire strand (messenger) of length $l_{1}$ and $l_{2}$ attached with a clamp to the damped conductor. The energy of vibrations is dissipated through friction caused by slippage between the messanger wires.

Another type of spiral damper is the Air Flow Spoiler. It can be used on conductors in order to balance aerodynamic lift forces which cause galloping. Usually, spoilers cover approx. $25 \%$ of the span length and are used in two groups $[4,5]$. The Torsional Damper and De-tuner is a modern damping device. It combines properties of a torsional damper and detuner. This damper increases the value of a critical speed of wind, above which galloping occurs, and reduces its amplitudes. In most cases, 2-3 dampers are installed along the span [6].

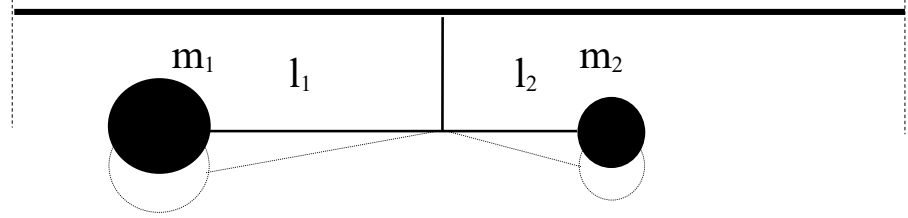

Fig. 1. Model of aeolian damper attached to the line.

\section{Determination of the effectiveness of aeolian damper}

Effectiveness of dampers were measured as the value of dissipation energy through the damper. The exciting force was input to the damper through the connection clamp.

Experiment stand consists of shaker, force sensor, accelerometer, amplifier, postprocessing analyser. Target frequencies were in the range of 4 to $100 \mathrm{~Hz}$, that can happen in real conditions in the case of aeolian vibrations. The aim of the experiment was to measure the acceleration/velocity and control the exciting force acting on the damper to determine the valu e of the total energy dissipated by the damper. The experiments were performed for fix damper's parameters: $m_{1}=1.8 \mathrm{~kg}, m_{2}=1.4 \mathrm{~kg}$, messengers length $l_{1}=240$ $\mathrm{mm} \mathrm{m}, l_{2}=190 \mathrm{~mm}$. Accelerometer and force transducer were mounted close to the clamp of the damper. The parameters of the measurements were fixed. A sweep rate of 0.2 decade/min was used. Clamp velocity was held constant at $0.1 \mathrm{~m} / \mathrm{s}$. The damper power is determined as [7] :

$$
P=F V \cos \phi
$$

Where: $P$ is the power [W], $F$ is the exciting force $[\mathrm{N}]$ - peak value, $V$ is the velocity of the damper clamp $[\mathrm{m} / \mathrm{s}], \phi$ is the phase value between the velocity and the force [degree].

During the experiments of forced vibration of two-mass dampers, the maximum of energy dissipation were observed: peaks no. 1 and 3 corresponding to the vibration of mass $m_{1}$ and peaks 2 and 4 for the mass $m_{2}$ Figure 2 . 


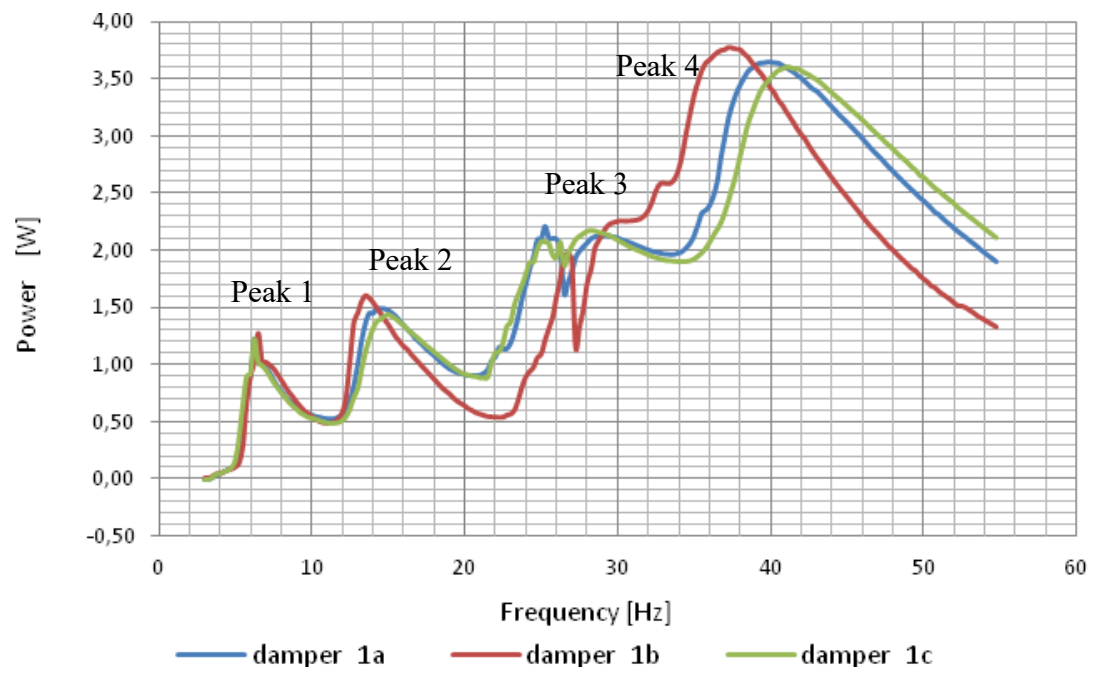

Fig. 2. Damper power curves.

Figure 2 shows the curves of energy dissipation in the frequency domain for three dampers of the same type. Maximum value of power dissipation is $1.3 \mathrm{~W}$ at frequency 6.5 $\mathrm{Hz}, 1.61 \mathrm{~W}$ at $14.85 \mathrm{~Hz}, 2.25$ at $25.5 \mathrm{~Hz}$ and $3.85 \mathrm{~Hz}$ at $37.6 \mathrm{~Hz}$.

\section{Vibration-impact dampers for controlling of the drilling dynamics}

All forms of drilling are accompanied by considerable vibrations, which have a deleterious effect on the life of the drillstring elements and the surface equipment, worsen the working conditions of the crews, and are responsible for an inefficient process of rock disintegration [8-10]. Analysis of the experimental data and the models of well-deepening processes that describe them has established that the axial static load and the drilling bit rotation speed must be increased to ensure greater mechanical speed and penetration with sufficient flushing. That possibility is limited by the growing drillstring vibrations, especially when drilling out very hard rock or when rocks with different mechanical properties alternate very frequently (e.g., in near-Carpathian regions). The following special vibrationprotecting devices must be used to solve the problems. The use of such devices in oil- and gas-well drilling has a specific nature: the vibrations need not be completely damped; a certain balance must be created between the dynamics of the drillstring and its level of vibration protection, which increases the drilling efficiency and at the same time improves the operating conditions of the drilling equipment.

Principal ways of decreasing the drillstring vibrations are the following [10]:

- isolation of vibrations and impacts by means of dampers, flexible downhole motor bit shafts and flexible couplings;

- screening of elastic waves propagating from the drilling bit by special "reflectors";

- preventing transverse vibrations and relaxation self-oscillations by decreasing the radial clearance between the tool joints and the hole walls with the installation of centralizers and centralizing reamers;

- dissipating of vibrations and changing of dynamic conditions of the drilling by means of dynamic dampers.

The diversity of geological and technical conditions has led to the development of a 
multitude of vibration protection methods and equipment. Only a handful of those multitudes of proposed designs are used in practice. The explanation for this is that under borehole conditions vibration protection means must meet very stringent requirements as to serviceability, longevity, and reliability. In view of this, particular interest is aroused by the dynamic damper designs based on the effect of collisions [10-13]. The dynamic conditions of the object connected with a vibration-impact damper are changed both by a redistribution of vibration energy from the object to the damper and by an increase in the vibration energy dissipation. Dynamic dampers of various designs have been proposed and put into use in oil and gas well drilling [10].

Figure 3, presenting a filled drill collar consisting of inner and outer pipes, 3 and 2. Pipe 3 is provided with a helical baffle plate 4 . The space between the pipes is often filled with balls 5 . The upper parts of pipes 2 and 3 are connected by a sub 1 and the lower parts, by a sub 6 and a nut 7 for pretensioning the inner pipe.

a)

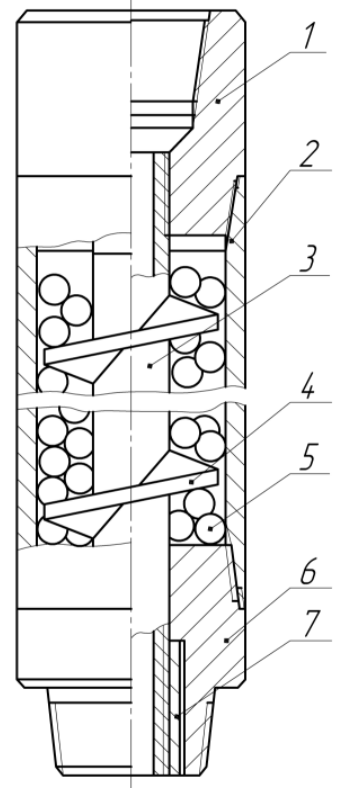

b)

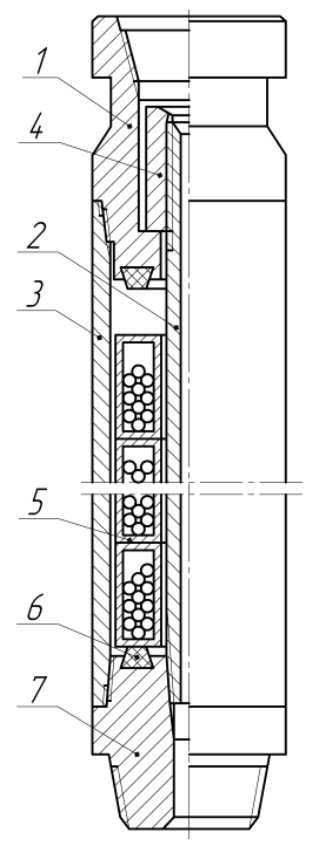

Fig. 3. (a) Filled drill collar: 1 is an upper sub, 2 and 3 are external and internal pipes, 4 is a helical baffle plate, 5 are balls, 6 is a lower sub and 7 is a nut; (b) Container type drill collar: 1 is an upper sub, 2 is a stem, 3 is a body, 4 is a nut, 5 are containers, 6 is an anvil and 7 is a lower sub.

The filled drill collar functions as follows. The pipe is connected to the drillstring by the upper sub 1 and the drilling bit is screwed onto the bottom sub 6. During drilling, the drilling bit vibrations are transferred to the filled colar. Longitudinal vibrations act on the mass of the balls 5 freely placed in the space. Those balls execute motions that are not synchronous with the motions of the inner and outer pipes and collide with the helical baffle plate 4 , whereupon they damp the longitudinal and transverse vibrations of the drilling bit, thus protecting the elements of the drill collar from the deleterious effects of the vibrations.

Torsional vibrations due to the repetitive braking of the drilling bit are particularly harmful to downhole motors. When the torsional moment of the drilling bit is increased and the drillstring rotation speed decreases abruptly, the free mass of the balls 5 tends to prolong the uniform motion. The mass acts on the filled drilling collar via the helical baffle 
4 and then on the drilling bit through the collar, thus facilitating uniform rotation of the drilling bit.

In addition to the models of dissipation energies in frictional shell damps $[14,15]$ the theoretical studies have been made of vibration damper systems containing one or several vibration-damping elements in an enclosed space. An attempt has thus been made to build an elastodissipative model of a bulk material [15-18], contained within a space, which is subject to longitudinal or torsional vibrational displacements. An expression was obtained for determining the dissipated energy of the bulk material in the space, executing harmonic vibrations:

$$
S=\frac{\pi m a^{2} \omega^{4} \Phi_{1}(\omega, \Delta)}{\sqrt{\left[k_{1}^{2}(a, \omega, \Delta)-\omega^{2}\right]^{2}+4 \mu^{2}(\omega) k_{1}^{2}(a, \omega, \Delta) \omega^{2}}},
$$

Where $m$ is the mass of the bulk material, $a$ is the amplitude of the main damping system, $\Delta$ is the clearence in the cavity, and $\omega \square$ is the resonance frequency that ensures a maximum dynamic coefficient. The characteristics of a quasi-elastodissipative body that appear in the expression are studied on the basis of a full-scale experiment; those characteristics are the mode coefficient $\Phi_{1}(\omega, \Delta)$, the first natural frequency of the bulk material $k_{1}(a, \omega, \Delta)$, and the dimensionless coefficient of equivalent viscous friction $\mu(\omega)$.

If $N$ hollow vibration dampers, partially filled with a bulk material, are connected to a drillstring, the logarithmic decrement of vibrations in the $j$ th mode is

$$
\delta_{j}^{\Sigma}=\frac{N+\Phi_{j}}{1+\Phi_{j}} \delta_{j}
$$

Where $\Phi_{j}$ is the total mass of balls in the instantaneous vibration damper.

From (3) we see that for a fixed total mass of bulk material the total logarithmic decrement of vibrations increases with the number of sections. That means that it is more convenient for vibration damping to make the vibration damper as a set of sections of short filled drill collarss. In practice, that qualitative conclusion has been adjusted for the results of an industrial experiment with allowance for the specific drilling conditions. Theoretical investigations and the experience from industrial experiments have led to an alternative modernized design of a container-type filled drill collar, Figure 3, $b$, consisting of upper and lower subs 1 and 7 , stem 2, body 3, nut 4, containers partially filled with a bulk material 5, and anvil 6 . The number of containers and the extent to which they are filled are chosen on the basis of the geological and engineering and technological conditions of the drilling. To increase the damping of torsional vibrations, the containers 5 can be provided with ball joints, which interact with longitudinal or helical grooves on the inner tube, and the space inside the containers is divided, by at least one vertical baffle. A number of container versions of inertial dampers with diameters of $142 \mathrm{~mm}, 170 \mathrm{~mm}$, and $240 \mathrm{~mm}$ have been designed.

\section{Conclusions}

Vibrations of overhead power line conductors caused by wind may lead to their destruction. Therefore, reducing the level of such vibrations is important due safety of the entire structure. Common methods of minimization of conductor vibrations are passive: proper 
shaping of the external surface of a conductor, a proper design of the conductor (selfdamping) and use of special damping devices, depending on the type of excitations.

At present, there is no way to completely reduce vibrations during galloping, for which amplitudes may reach high values. According to the research literature, Air Flow Spoilers and torsional dampers are most effective in minimizing conductor galloping, whereas Stockbridge dampers are still the most efficient devices for aeolian vibrations and spiral dampers are excellent for very small diameter of conductors.

The simplicity of design, ease of manufacture, and operating efficiency predetermined extensive use of filled inertial dampers in deep oil- and gas-well drilling in Vorcarpathian region. The economic benefits resulting from the technical and economic drilling indicators attained are: mechanical speed, footage per bit, and reduction of failures of the drilling tool.

\section{References}

1. I. Gołębiowska, M. Dutkiewicz, B. Usewicz, TTS, 12/2015, 5, 2544-2548 (2015)

2. M. Farzaneh, Atmospheric icing of power networks (Springer, 2008)

3. A. Luongo D. Zulli, G. Piccardo, Comput. and Struct., 87,15-16, 1003-1014 (2009)

4. Conductor Galloping Basics, Report prepared by Preformed Line Products (2016)

5. State of the art of conductor galloping. A complementary document to "Transmission line reference book - Wind induced conduction motion Chapter 4: Conductor galloping", based on EPRI Research project 792. CIGRE ad hoc SC (2005).

6. A. Vinogradov, I. S. Iosif, L. Jean-Louis, Int. Conf. Energy of Moldova, 223-228 (2012)

7. AR Products LLC 2015 http://arproducts.org/, (data per day 30.09.2016)

8. M. I. Pekhn'o, A. I. Tsikhan, Oil and Gas Well Drilling with Bottom Collar Dampers (Nauk. Dumka, Kiev, 1971)

9. V. V. Simonov, E. K. Yunin, Influence of Vibrational Processes on Drilling Tool Work (Nedra, Moscow, 1977)

10. A. S. Velichkovich, S. V. Velichkovich, V. M Shopa, A Set of Vibration Dampers for Controlling Dynamic Drillin Stem Conditions (IFNTUNG, Ivano-Frankivsk, 2000)

11. R. D. Friend, V. K. Kinra, J. Sound Vib., 233, 93-118, (2000)

12. A. S. Velichkovich, Chem. Petrol. Eng., 43, 7-8, 458-461 (2007)

13. Z. Lu, Z. Wang, S. F. Masri, X. Lu, Struct. Control and Health Monit., 25, e2058 (2018)

14. V. M Shopa, I. I. Popadyuk, I. P. Shatskii, Sov. Eng. Res., 9, 3, 42-44 (1989)

15. S. V. Velichkovich, I. I. Popadyuk, I. P. Shatskii, V. M Shopa, Strength Mater., 23, 3, 279-281 (1991)

16. A. A. Kobrinskii, A. E. Kobrinskii, Vibro-Impact Systems (Nauka, Moscow, 1978)

17. V. Babitsky, Theory of Vibro-Impact Systems and Applications (Springer, 1998)

18. M. Saeki, J. Sound Vib., 281, 3-5, 1133-1144 (2005) 